\title{
Specific Radioactive Activity
}

National Cancer Institute

\section{Source}

National Cancer Institute. Specific Radioactive Activity. NCI Thesaurus. Code C94986.

A quantitative measure of the radioactive emissions per unit time per unit mass. 